\title{
Identification of soluble tissue-derived biomarkers from human thyroid tissue explants maintained on a microfluidic device
}

\author{
ANDREW RILEY $^{1}$, HEIDI JONES ${ }^{2}$, JAMES ENGLAND ${ }^{2}$, DMITRIY KUVSHINOV ${ }^{3}$, \\ VICTORIA GREEN $^{1}$ and JOHN GREENMAN ${ }^{1}$ \\ ${ }^{1}$ Faculty of Health Sciences, University of Hull, Hull HU6 7RX; \\ ${ }^{2}$ Department of ENT, Hull University Teaching Hospitals NHS Trust, Castle Hill Hospital, Hull HU16 5JQ; \\ ${ }^{3}$ Faculty of Engineering, University of Hull, Cottingham Road, Hull HU6 7RX, UK
}

Received April 21, 2021; Accepted June 9, 2021

DOI: $10.3892 / 01.2021 .13041$

\begin{abstract}
Although a large cohort of potential biomarkers for thyroid cancer aggressiveness have been tested in various formats in recent years, to the best of our knowledge, thyroglobulin and calcitonin remain the only two established biomarkers associated with thyroid cancer management. Our group has recently validated a novel means of maintaining live, human ex vivo thyroid tissue within a tissue-on-chip format. The present pilot study aimed to interrogate the tissue effluent, containing all the soluble markers released by the tissue samples maintained within the devices' tissue chamber, for the presence of markers potentially associated with thyroid cancer aggressiveness. Culture effluent from tissue samples harvested from 19 individual patients who had undergone thyroidectomy for the treatment of suspected thyroid cancer was assessed, first using a proteome profiler ${ }^{\mathrm{TM}}$ angiogenesis array kit. Patients were subcategorised as 'aggressive' if they possessed a minimum of N1b level metastases, whilst 'non-aggressive' samples were T3 or lower without evidence of multifocality; and contralateral healthy thyroid tissue was harvested for comparative studies. Levels of Serpin-F1, vascular endothelial growth factor, Thrombospondin-1 and chemokine (C-C motif) ligand were significantly altered and, thus, were further investigated using ELISA to allow for quantitative analysis. The concentration of serpin-F1 was significantly increased in the effluent of aggressive thyroid cancer tissue when compared with levels released by both non-aggressive and benign samples. The present study demonstrated the usability of microfluidic technology for the analysis of the ex vivo tissue secretome in order to identify novel biomarkers.
\end{abstract}

Correspondence to: Professor John Greenman, Faculty of Health Sciences, University of Hull, Cottingham Road, Hull HU6 7RX, UK E-mail: j.greenman@hull.ac.uk

Key words: biomarker, thyroid, thyroid cancer, microfluidics, serpin F1

\section{Introduction}

The majority of thyroid cancers have an excellent prognosis, although the presence of locoregional or distant metastases has a considerable negative effect on patient survival and morbidity (1). At present, thyroglobulin and calcitonin are the only two established biomarkers associated with thyroid cancer management and are the subject of active surveillance within patient serum following thyroidectomy to indicate disease recurrence $(2,3)$. However, no markers associated with thyroid cancer aggressiveness have been incorporated into clinical practice.

In recent years various molecular markers have been extensively studied as predictors of patient outcome. For example, the BRAFV600E mutation has been associated with aggressive clinical behaviours such as metastatic spread or recurrent tumour burden (4). In addition, multiple microRNAs (miRs), such as miR-221, miR-222 and miR-146b have been reported as overexpressed in papillary thyroid cancer (PTC) specimens and may also be associated with disease aggressiveness (5-7). A wide range of both soluble and tissue-retained biomarkers for thyroid cancer have been studied previously (Table I). The expression of biomarkers within a tissue, although interesting from a biological perspective, commonly do not reflect the level within circulation (8), and it is clearly impractical to sample routinely making them less attractive for clinical utilisation. On the other hand, patient sera, potentially offer a higher degree of translatability for the identification of progression and disease-specific biomarkers (9-11); thus far both serum VEGF-C and MMP-2 have been correlated with thyroid tumour metastases $(11,12)$.

The use of a precision cut tumour slice microfluidic device to maintain ex vivo thyroid cancer tissue has been demonstrated previously, and offers a novel means of assessing the levels of soluble markers released specifically from the malignant tissue (13). Proteins involved in the process of blood vessel formation are ideal candidates as markers of cancer progression and metastasis, with angiogenesis being fundamental to these processes (14). The current research aimed to elucidate the levels of common angiogenic biomarkers within effluent produced in the described system and correlating the findings with the clinical features of the patients. 


\section{Materials and methods}

Patient sample acquisition. Human thyroid tissue samples were collected during thyroidectomy following written informed consent under ethical approval from Northeast-Newcastle and North Tyneside Research Ethics Committee (15/NE/0412) and Hull University Teaching Hospitals NHS Trust R\&D (R1925). Where possible, tissue was excised from the contralateral lobe alongside the malignant sample (aggressive $n=9$; non-aggressive $n=8$; pathologically benign $(n=3$; Table II). Tissues were classed as 'aggressive' if they presented clinically with a minimum of N1b level metastases [tumour spread beyond the central compartment, including unilateral (on 1 side of the neck), bilateral cervical (on both sides of the neck), contralateral cervical (the opposite side to the tumour), or mediastinal (chest) lymph nodes]. 'Non-aggressive' samples were T3 or lower (localised to the thyroid gland) without evidence of multifocality.

Microculture device set up. Tissue samples were 'live' sliced (350-500 $\mu \mathrm{m})$ in ice-cold PBS using a vibratome (Leica VT1200S, Milton Keynes) with a blade speed of $0.1 \mathrm{mms}^{-1}$ and amplitude of $2.5 \mathrm{~mm}$. A skin biopsy punch (Stiefel) was used to generate a precision cut tumour slice (PCTS), $5 \mathrm{~mm}$ in diameter. Each PCTS was weighed before insertion into the microculture device. Average PCTS wet weight was $15.92 \pm 2.41 \mathrm{mg}$. A schematic demonstrating the study design is shown in Fig. 1. A previously described PCTS device (13) was used to house the thyroid tissue whilst being perfused at a rate of $2 \mu 1 \mathrm{~min}^{-1}$ with Dulbecco's modified eagles medium (DMEM; GE Healthcare) containing 10\% (v/v) heat inactivated foetal bovine serum (FBS; Biosera), penicillin/streptomycin $(0.1 \mathrm{U} / \mathrm{ml}$ and $0.1 \mathrm{mg} / \mathrm{ml}$ respectively; GE Healthcare), $0.4 \mathrm{mM}$ glutamine (GE Healthcare), $2.5 \mu \mathrm{g} / \mathrm{ml}$ Amphotericin B (Life Technologies, Paisley, UK), thyrotropin (TSH; $2 \mathrm{mIU} / \mathrm{l})$ and sodium iodide $(0.1 \mu \mathrm{g} / \mathrm{ml})$. The culture device (shown in Fig. 2) was maintained at $37^{\circ} \mathrm{C}$ for $72 \mathrm{~h}$; medium coming off the device was collected after $2 \mathrm{~h}$ culture, then once per day thereafter and frozen $\left(-80^{\circ} \mathrm{C}\right)$ prior to use in the assays. Effluent was collected from at least 2 patient-derived tissue slices from each patient, which had been cultured in parallel, was used in this study in order to minimise the impact of tumour tissue heterogeneity.

Proteome profiler ${ }^{T M}$ angiogenesis array. An Array Kit (Proteome Profiler ${ }^{\mathrm{TM}}$; R\&D Systems) was used, as directed, to detect the presence of 55 angiogenesis-related proteins released from the thyroid tissue whilst maintained on the microfluidic device. Following a $1 \mathrm{~h}$ incubation of the array membranes with blocking buffer, detection antibody cocktail, reconstituted in $\mathrm{dH}_{2} \mathrm{O}(15 \mu \mathrm{l})$, was added to $700 \mu \mathrm{l}$ of thawed and centrifuged (300 x g; to remove cellular debris) culture effluent collected following a $72 \mathrm{~h}$ incubation on the microfluidic device. The $72 \mathrm{~h}$ timepoint was chosen as data produced previously demonstrated a stabilisation of cellular death (such as tissue LDH leakage) within $72 \mathrm{~h}$ incubation (13). Effluent from a minimum of 2 explants from each patient, cultured in parallel, was utilised. The sample volume was made up to $1.5 \mathrm{ml}$ using buffer provided and incubated for $1 \mathrm{~h}$ at room temperature, before adding to the membranes in separate wells of a 4-well multi-dish (provided). The membranes and samples were incubated overnight at $4^{\circ} \mathrm{C}$ on a rocking platform before being washed in $20 \mathrm{ml}$ wash buffer (provided) for 3x10 min. Streptavidin-HRP $(1: 2,000)$ was added to each membrane $(2 \mathrm{ml})$ and incubated for $30 \mathrm{~min}$ with gentle agitation. The membranes were washed a further three times before antibody binding was detected with chemiluminescence (Thermo Fisher Scientific) and autoradiography. Dot densitometry was then analysed using the 'analyse gels' function within ImageJ Fiji software (open source; https://imagej.net/Fiji). The mean densitometry of each protein duplicate was calculated and expressed as a percentage of the average density of the 6 positive-control dots within the membrane. The resultant expression intensities were correlated to thyroid disease aggressiveness, by comparing their levels in three tissue groups: benign, non-aggressive and aggressive.

Quantification of factor expression using ELISA. Following initial detection of biomarkers of interest using a Proteome Profiler $^{\mathrm{TM}}$ angiogenesis array, marker specific ELISAs were utilised, allowing fully quantitative evaluation of their levels within microculture effluent. ELISAs [CCL2 (DY279); serpin-F1 (DY1177-05); R\&D, Oxford, UK] were carried out according to the manufacturer's instruction. Effluent samples were combined from a minimum of two replicate culture devices set-up from each resected patient sample (aggressive $n=9$; non-aggressive $n=8$; benign $n=3$ ). Due to limitations of effluent availability, effluent collected after $96 \mathrm{~h}$ culture was tested by ELISA (as opposed to the $72 \mathrm{~h}$ timepoint used for Proteome Profiler experiments). Following removal of the capture antibody and washing of the plate with the wash buffer provided, effluent (100 $\mu \mathrm{l} /$ well) samples were added to the plate in duplicate alongside prepared standards, covered with an adhesive strip, and incubated at room temperature for two hours. Following three washes with TBS, incubation with matched biotinylated detection antibodies was carried out for a further two hours before addition of the streptavidin-biotin complex for $20 \mathrm{~min}$. Colour development was induced by the addition of substrate reagent containing stabilised tetramethylbenzidine (TMB; R\&D Systems). The optical density of each well was measured at $450 \mathrm{~nm}$ with wavelength correction at $570 \mathrm{~nm}$. The mean of duplicate readings was taken for each sample. A 4-parameter logistic curve fit was used to produce a standard curve from which protein concentration in the unknown samples was determined.

Statistical analysis. Data were grouped into results for benign, non-aggressive and aggressive tumours and analysed using one-way ANOVA and post-hoc Tukey/Sidak tests on GraphPad Prism 8.0. All data is reported as mean \pm SEM unless otherwise stated.

\section{Results}

Semi-quantitative measurement of angiogenic factors release from thyroid tissue maintained on a microfluidic device using a Proteome Profiler ${ }^{T M}$ array. The analysis of microfluidic culture effluent for the presence of 55 soluble angiogenesisrelated protein factors, using the proteome profiler ${ }^{\mathrm{TM}}$ array, demonstrated that 22 of those factors were detectable (Fig. 3). 





While the majority of detectable factors showed relatively little variance between the three disease sub-groups, inter-group variance existed in the cases of chemokine (C-C motif) ligand 2 (CCL2), Serpin-F1, vascular endothelial growth factor (VEGF) and Thrombospondin-1 (TSP-1; Fig. 3). The effluent of aggressive thyroid cancers contained a significantly higher level ( $72.85 \pm 21.38$ a.u.; $\mathrm{P}=0.0002$ and $\mathrm{P}=0.04)$ of $\mathrm{CCL} 2$ when compared to the effluent of non-aggressive $(32.06 \pm 13.57$ a.u.) and benign ( $39.72 \pm 32.96$ a.u.) thyroid tissue, respectively. No significance was detected between the levels of CCL2 released by benign and non-aggressive tumour tissue.

In addition, the level of Serpin-F1 increased with disease severity; benign thyroid tissue released $22.99 \pm 8.28$ a.u., compared with $35.06 \pm 10.64$ a.u. in non-aggressive cancer tissue and $64.87 \pm 8.25$ a.u. in the effluent of aggressive thyroid cancer tissue explants. Significance was detected when comparing the levels of Serpin-F1 in aggressive with both non-aggressive $(\mathrm{P}=0.008)$ and benign thyroid tissue $(\mathrm{P}=0.005)$. In contrast, VEGF release decreased with disease severity and was found to be significantly lower in concentration in the effluent collected from aggressive thyroid tumours compared to that collected from benign thyroid tissue (28.79 \pm 9.46 vs. $60.69 \pm 12.02$ au.; $\mathrm{P}=0.044)$. Finally, although not significant, thrombospondin-1 was markedly higher in effluent from the aggressive tissue sub-group, when compared to the non-aggressive group $(32.86 \pm 8.06$ vs . 11.46 \pm 2.99 a.u.; $\mathrm{P}=0.08$ ). Further, benign tissue appeared to release a higher level of thrombospondin-1 than the counterpart non-aggressive tissue, although the difference was minimal and there was large variation in the levels.

Quantification of factor expression using ELISA. Following initial, semi-quantitative biomarker, analysis within the culture supernatant, and due to a limited volume of available supernatants for subsequent analyses, Serpin F1 and CCL2 were chosen to be studied by ELISA as they represented the most interesting potential biomarkers of thyroid disease aggressiveness due to the clear differences in levels between tissue types. The concentration of Serpin-F1 within the effluent of aggressive thyroid cancer tissue $\left(4,038 \pm 518.01 \mathrm{pg} \cdot \mathrm{ml}^{-1}\right)$ was significantly higher $(\mathrm{P}=0.005)$ than that from non-aggressive cancer tissue $\left(1,450.48 \pm 532.34 \mathrm{pg} \cdot \mathrm{ml}^{-1}\right)$ and benign thyroid tissue $\left(\mathrm{P}=0.01 ; 1,104.28 \pm 95.24 \mathrm{pg} \cdot \mathrm{ml}^{-1}\right.$; Fig. $\left.4 \mathrm{~A}\right)$. The overall pattern of Serpin F1 release detected by ELISA directly mirrored the pattern detected by the aforementioned array experiments. Four of the eight patients within the 'aggressive' group $(1,3,4,9)$ experienced disease progression; furthermore, three of those four patients $(1,3,9)$ passed away due to complications with progression of their thyroid disease $750 \pm 236$ days following their initial thyroid cancer surgery. No significant difference in factor secretion existed between those patients who experienced a fatal progression of their disease and those who did not. All patients within the 'non-aggressive' subcategory are currently alive.

The concentration of CCL2 detectable by ELISA across the three tissue types was above the top standard supplied $\left(1,000 \mathrm{pg} \cdot \mathrm{ml}^{-1}\right)$. Due to the limited volumes of culture supernatant available, it was not possible to dilute and repeat the analysis, thus the results were extrapolated and therefore should be regarded with caution and may be why the pattern observed (decreasing with disease severity) was not the same 
Table II. Clinicopathological features of thyroid patients, ordered by descending tumour-node-metastasis stage.

\begin{tabular}{clcccc}
\hline Patient & Staging & Age, years & Sex & Tissue type & Survival, months \\
\hline 1 & T4aN1b & $70-80$ & F & A & $16^{\mathrm{a}}$ \\
2 & T4aN1b & $70-80$ & F & A & $23^{\mathrm{a}}$ \\
3 & T4N0M1 & $50-60$ & F & A & $29^{\mathrm{a}}$ \\
4 & T4aN1bMX & $70-80$ & M & A & 28 \\
5 & T3N1bMX & $20-30$ & F & A & 43 \\
6 & T3bN1aMX & $40-50$ & M & A/BC & 35 \\
7 & T3aN1bM0 & $20-30$ & F & A & 31 \\
8 & T3aN1bMX & $30-40$ & F & A & 32 \\
9 & T3N1bMX & $40-50$ & F & A & $40^{\mathrm{a}}$ \\
10 & T3aNXMX & $60-70$ & F & L & 28 \\
11 & T3aNXMX & $50-60$ & F & L & 47 \\
12 & T2NXMX & $40-50$ & M & L & 23 \\
13 & T1aNXMX & $50-60$ & F & L & 33 \\
14 & T1NXMX & $60-70$ & F & L & 33 \\
15 & T1aNXMX & $10-20$ & M & L & 30 \\
16 & T1aNXMX & $40-50$ & F & L & 35 \\
17 & T1bNXMX & $40-50$ & M & L & 25 \\
18 & - & $50-60$ & F & BC & 23 \\
19 & - & $60-70$ & F & BC & 47 \\
\hline
\end{tabular}

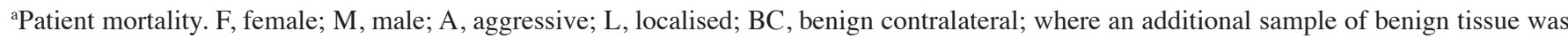
derived from the contralateral thyroid lobe at the time of surgery.

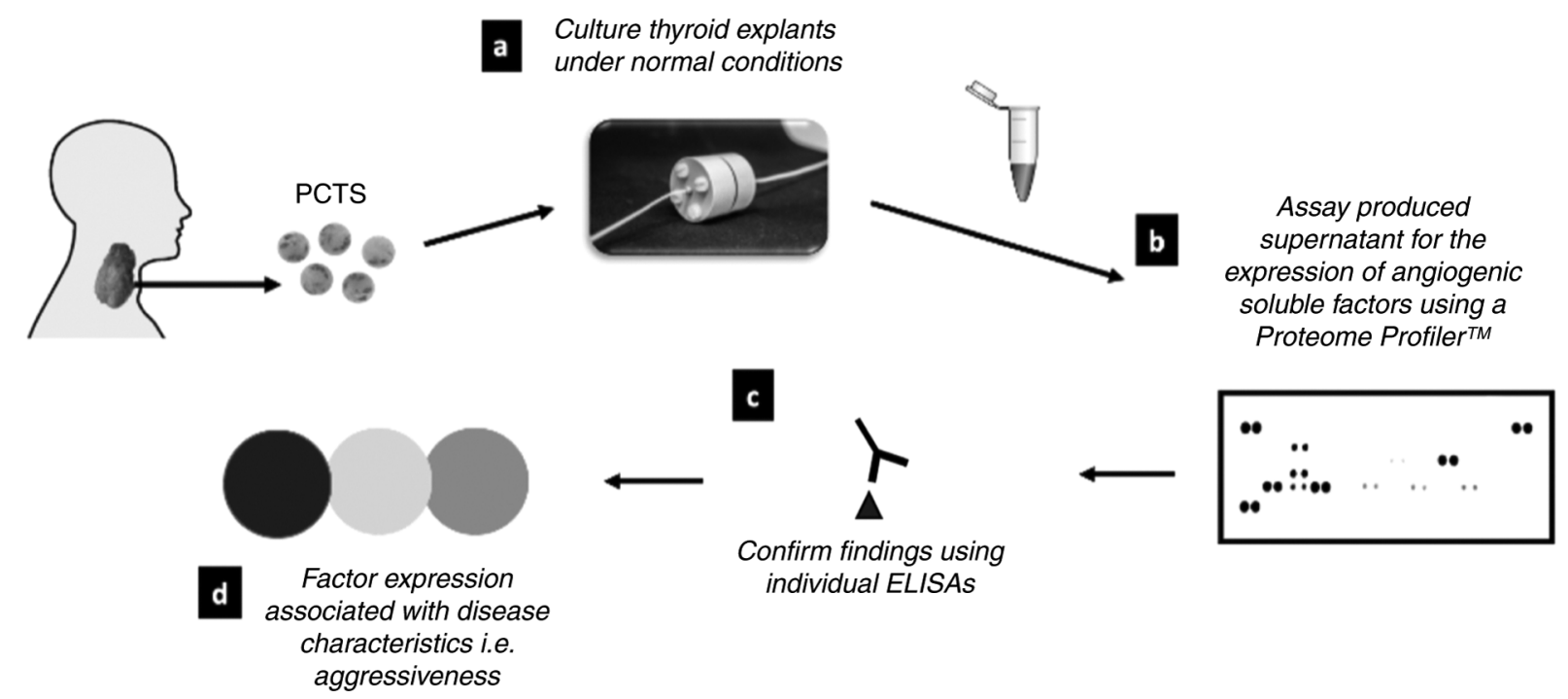

Figure 1. A schematic showing the biomarker experiment workflow. (A) Culture supernatant produced by thyroid tissue explants maintained within the microfluidic device was stored within polypropylene tubes at $-80^{\circ} \mathrm{C}$. (B) Supernatants assayed using a proteome profiler ${ }^{\mathrm{TM}}$ array to provide preliminary data pertaining to angiogenic factor release. (C) Two most strongly modulated factors [Serpin-F1 and chemokine (C-C motif) ligand 2] were investigated individually using ELISA to provide quantitative data. (D) Results associated with disease characteristics. PCTS, precision cut thyroid slice.

as detected in the array experiments (Fig. 4B). No significant differences between the tissue cohorts were observed.

\section{Discussion}

A number of previous studies have investigated whether quantifiable changes in protein expression can be used diagnostically or prognostically for thyroid malignancies, especially as biomarkers for disease characteristics such as lateral neck metastasis in thyroid cancer (11). As is the case for most cancers ( $>90 \%$ cancer-related deaths are due to tumour invasion), metastasis remains one of the main reasons for patient mortality in PTC $(15,16)$. Currently no clinical utilised biomarkers of thyroid cancer invasiveness or metastasis exist. 

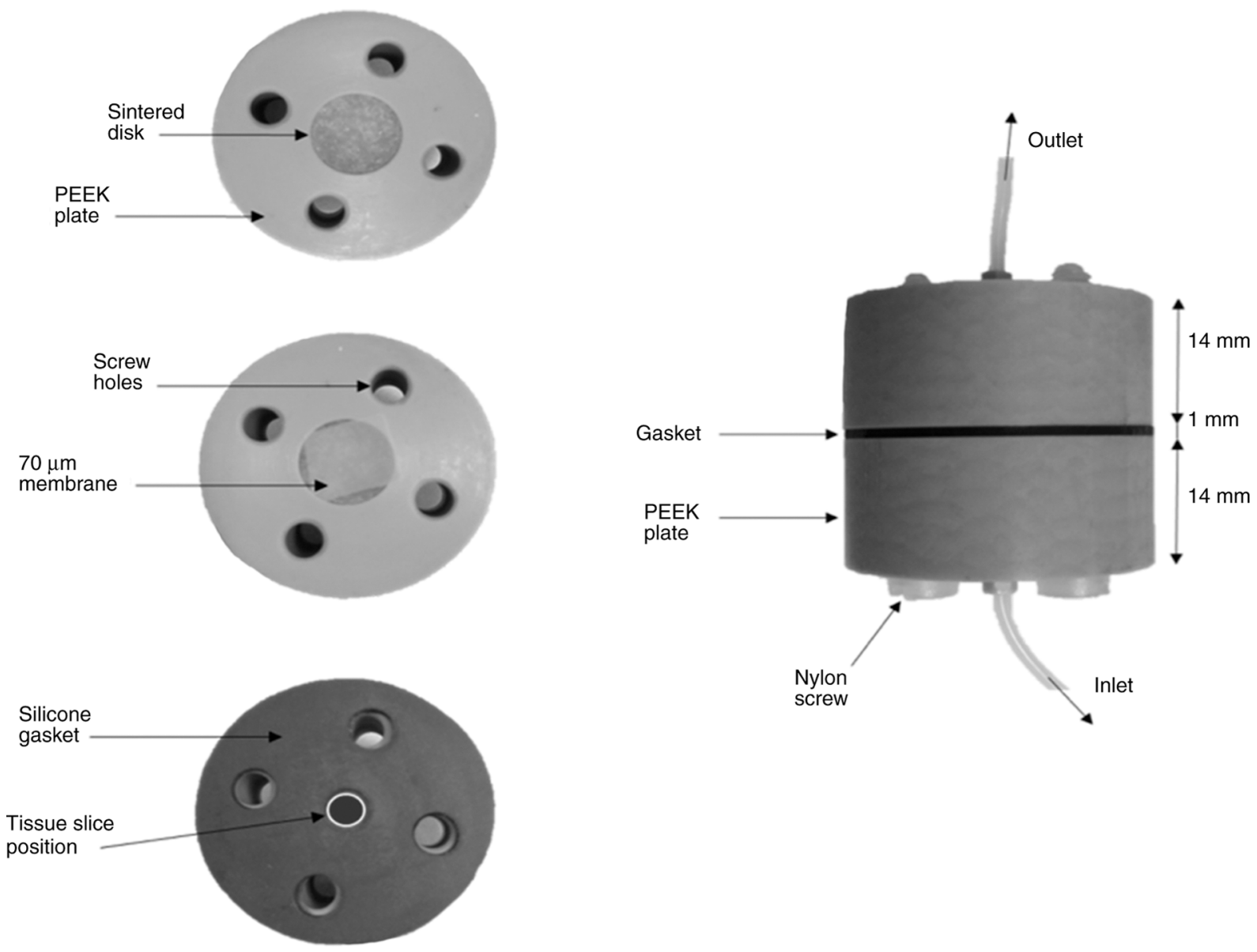

Figure 2. A composite image showing the microfluidic device employed within the current study. Left: PEEK plates (30-mm diameter) contain a 10-mm glass sintered disk situated in an adequately sized cavity to ensure the disk is flush with the internal plate surface. The lower disc is covered with a 70- $\mu \mathrm{m}$ membrane before the gasket is put in place, creating a central area for the tissue to be housed (bottom left). Threaded holes (3-mm) through the centre of the PEEK allow for connection of the inlet and outlet tubing via a CapTite ${ }^{\mathrm{TM}}$ fitting. Right: Assembled PEEK MF device held together with nylon screws. PEEK, polyether ether ketone.

Effluent samples from thyroid patient tumour tissue were grouped into three categories: Aggressive, non-aggressive and benign thyroid tissue. Culture effluent was initially analysed semi-quantitatively; of the 55 proteins investigated, a total of 22 proteins were detectable following their release by ex vivo thyroid tissue. Four of the 22 detectable proteins were differentially expressed depending on the thyroid tissue group from which they were derived. Levels of Serpin-F1, CCL2, and Thrombospondin-1 were all significantly higher in the effluent derived from aggressive thyroid cancers than those which had not metastasised. VEGF, on the other hand, was inversely correlated with aggressiveness; appearing to be released in lesser quantities by aggressive thyroid tissue, comparatively. Due to logistical difficulties regarding the quantity of culture effluent produced by on-chip maintenance of thyroid tissue explants, fully quantitative analysis was carried out on Serpin-F1 and CCL2 by ELISA only, as those factors appeared most profoundly modulated between the subgroups.

Serpin-F1, also known as pigment epithelial-derived factor, is a $50-\mathrm{kDa}$ glycoprotein with numerous biological functions including antiangiogenic and anti-tumorigenesis, and was initially purified from conditioned medium from human retinal pigment epithelial cells (17). The protein is commonly expressed in normal tissues (18) and to a lesser extent, in malignant tissues (19), in contrast to the findings in the current study. Approximately a decade after the proteins' initial discovery it was observed to be a potent inhibitor of angiogenesis, acting as a major antagonist to a range of pro-angiogenic factors such as VEGF; multiple studies have shown an inverse relationship in the expression of both serpin-F1 and VEGF $(20,21)$. In addition to its anti-angiogenic activity, serpin-F1 has been demonstrated as able to induce tumour cell re-differentiation and block tumour cell invasion and metastasis $(22,23)$. These anti-tumour effects of serpin-F1 have been demonstrated in a range of human cancers such as prostate (23), ovarian (24) and glioma (25). A previous study carried out by Lv et al utilising immunohistochemistry (IHC) and RT-qPCR established a correlation between the reduced expression of serpin-F1 in the thyroid and lymph node metastasis, extrathyroidal invasion and $\mathrm{BRAF}^{\mathrm{V} 600 \mathrm{E}}$ mutation in cases of papillary thyroid cancer (26). Although these findings apparently contradict the results obtained for serpin-F1 release in the current study, the two sets of data should be compared with caution; as Lv et al studied tissue-specific levels of the molecule, the current study investigated the levels released directly from the tissue.

CCL2 is a chemokine produced by a wide range of cell types including fibroblasts, endothelial and tumour cells (27). It has previously been demonstrated that CCL2 is overexpressed by a range of cancer types such as melanoma, ovarian, breast, and 


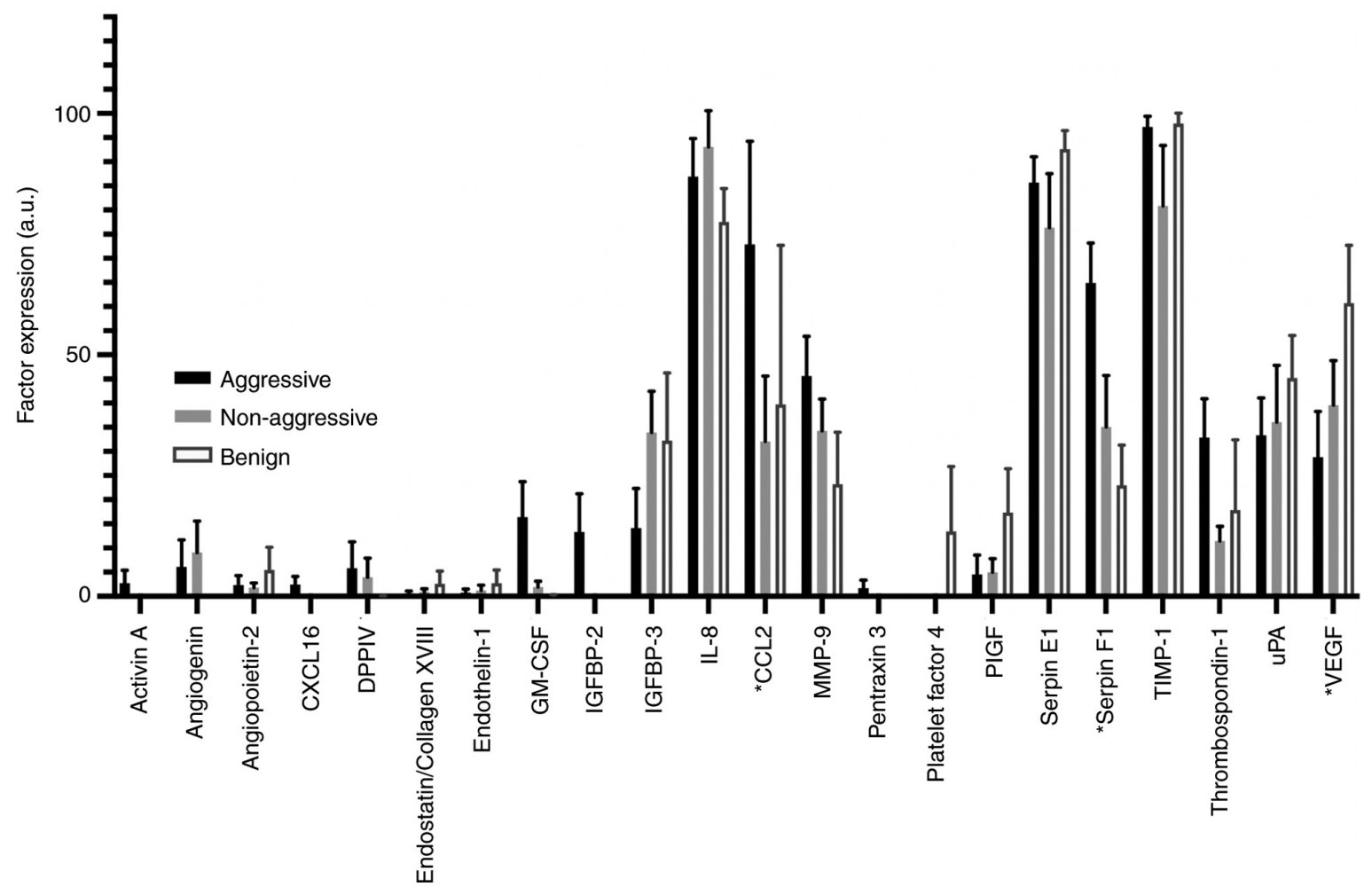

Figure 3. Bar chart displaying the relative expression of 22 detectable angiogenic factors released by human thyroid explants (aggressive $\mathrm{n}=7$; non-aggressive $\mathrm{n}=8$; benign $\mathrm{n}=3$ ) cultured within the novel microfluidic device. Of those 22 factors detected, CCL2, Serpin-F1 and VEGF demonstrated significant variation between the three tissue subgroups to some degree when significance was tested using a one-way ANOVA. Data produced were used to guide marker selection for subsequent fully quantitative, ELISA analysis. "P $<0.05$ between the three tissue subgroups. a.u, absorbance units; CXCL16, chemokine (C-X-C motif) ligand 16; DPPIV, dipeptidyl peptidase-4; GM-CSF, granulocyte macrophage colony-stimulating factor; IGFBP, insulin-like growth factor-binding protein; CCL2, chemokine (C-C motif) ligand; MMP, matrix metalloproteinase; PIGF, phosphatidylinositol-glycan biosynthesis class F; TIMP, Tissue inhibitor of metalloproteinases; uPA, urokinase-type plasminogen activator; VEGF, vascular endothelial growth factor.

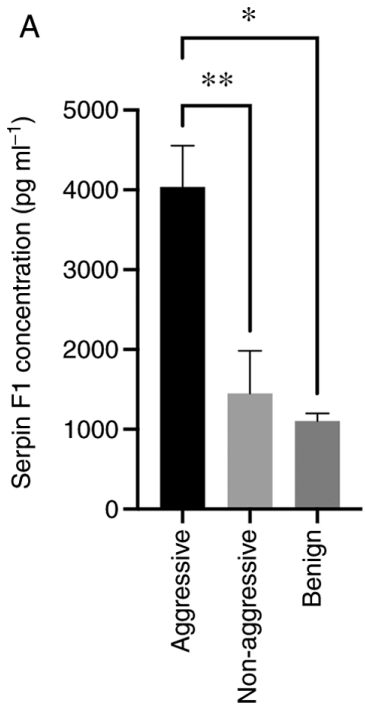

B

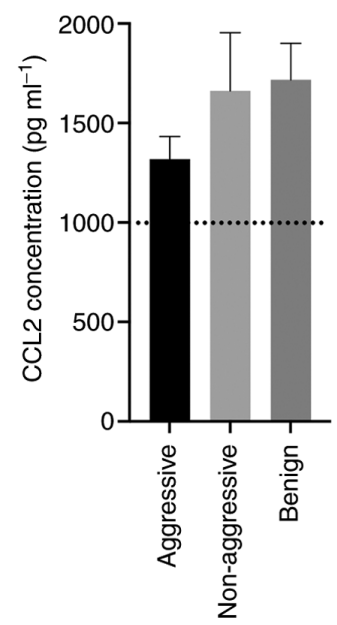

Figure 4. Graphs illustrating the quantitative analysis of serpin-F1 and CCL2 concentration within culture effluent. (A) Serpin-F1 release as detected by ELISA. (B) Mean CCL2 release as detected by ELISA. All values fell above the maximal reference value $\left(1,000 \mathrm{pg} \mathrm{m}^{-1}\right)$ and were extrapolated as a result. Aggressive $n=7$; non-aggressive $n=7$; benign $n=3$. Data presented as mean $\pm \mathrm{SEM} ;{ }^{*} \mathrm{P}=0.01,{ }^{* *} \mathrm{P}=0.005$. CCL2, chemokine (C-C motif) ligand.

oesophageal (28-31). Furthermore, increased CCL2 expression has been correlated with poor prognosis and advanced stage in cancer types such as prostate and oesophageal $(32,33)$ as well as predicting recurrence and vascular invasion in breast cancer $(30,34)$. Importantly, increased CCL2 expression, was significantly correlated with lymph node involvement and poor prognosis in thyroid cancer tissue $(35,36)$. These scant findings in the current literature appear to agree with the current results regarding CCL2 release by thyroid cancer tissue. However, as was the case with Lv et al who investigated Serpin-F1 release, Tanaka's study was carried out using IHC to assess tissue-specific marker expression, whereby the current study tested the level of released, soluble, CCL2.

Thrombospondin-1 is a $450 \mathrm{kDa}$ homotrimeric glycoprotein with diverse functionality such as the modulation of endothelial cell adhesion, motility, and growth, mediated through interaction between its structural domains and multiple cell-surface molecules and is produced by a range of cell types including platelets, endothelial cells, cancer cells and circulating immune cells $(37,38)$. In thyroid cancer, TSP-1 has been shown to be upregulated and mediate invasiveness and aggressiveness in B-RAF ${ }^{\mathrm{V} 600 \mathrm{E}}$ mutant tumours; murine implantation of TSP-1 knockdown cancer cells yielded significantly smaller tumours by volume, and fewer metastases compared with control (39). Further, Soula-rothhut and colleagues proposed that TSP-1 is a positive effector in thyroid tumorigenesis; they used an in vitro model to demonstrate the proteins' stimulation of cell proliferation, migration and invasion in FTC133 and FTC-238 thyroid cancer cells (40). The results found in 
the current study would appear to agree with the evidence for the role of TSP-1 in mitigating tumour invasion since a significantly higher concentration of TSP-1 was detected in the effluent of aggressive thyroid cancer tissue compared to that of non-aggressive thyroid cancer tissue. However, in contrast, TSP-1 has been shown to inhibit kidney cancer cell migration in vitro (41). In addition, oesophageal cancer patients with low tumour expression of TSP-1 were associated with worse progression free survival (42). This incongruence between studies investigating the role of TSP-1 in cancer tissues reveals a potentially multifaceted, pleiotropic role which depends on both the tumour microenvironment and downstream receptor presence (43). VEGF is a pro-angiogenic growth factor which binds one of two receptors (VEGFR-1 and VEGFR-2), both of which are expressed on the surface of endothelial cells and transduce pro-angiogenic signalling (44). VEGF is a key mediator of angiogenesis in tumour tissue, where it is up regulated due to oncogene activation and hypoxia within the tumour microenvironment (45). Interestingly, a previous study carried out by Soh and colleagues found an increased level of VEGF secretion by thyroid cancer cells when compared to their benign counterparts. The discrepancy is perhaps as the group employed fully quantitative ELISA, which was not possible in the current study (46). A different group discovered that serum VEGF was more likely to be elevated in patients with differentiated thyroid cancer, as opposed to those suffering poorly differentiated thyroid cancer (47). It would be possible in future studies to investigate the effect of hypoxia on the relative levels of VEGF release by ex vivo thyroid tissue.

The logical next stage of the work would involve the collection of data concerning tissue-specific levels of the proteins investigated, by separate means such as IHC, in order to correlate the tumour microenvironment with secreted products. Furthermore, maximising the quantity of tissue collected at the point of surgical resection would increase the number of tissue slices able to be cultured in parallel. Thus, an increased volume of effluent could be collected and combined, strengthening the statistical analyses, and improving the clinical applicability of the system. However, the quantity of human tissue provided will always be a limiting factor, and thus focussing on a smaller subset of targets is an equally valuable approach. In addition, a potentially interesting avenue of work would be the investigation of serpin-F1 and CCL2 in vitro and in vivo, assessing how inhibition of these proteins affects thyroid cancer development and aggressiveness.

The data presented within this manuscript demonstrates first and foremost the application of microfluidic technology for the detection of soluble tissue-derived factors. This is, to the best of the authors knowledge, the first time effluent derived from the microfluidic culture of ex vivo human thyroid tissue has been tested for the expression of a panel of angiogenic markers. Initial testing of effluent identified four potential markers of thyroid cancer progression/aggressiveness (Serpin-F1, CCL2, VEGF, and TSP-1). Further testing by ELISA demonstrated the significant modulation of serpin-F1 release according to tissue severity, and therefore its' potential as a marker of thyroid cancer aggressiveness. An interesting facet of the data presented herein is the prediction of disease progression by elevated Serpin-F1 and CCL2 in culture effluent at the point of testing. These data represent a pilot study, demonstrating the correlation between a number of identified markers and thyroid cancer aggressiveness.

\section{Acknowledgements}

Not applicable.

\section{Funding}

The present study was funded by The Committee of The British Association of Endocrine and Thyroid Research (grant no. 256168).

\section{Availability of data and materials}

The datasets used and/or analysed during the current study are available from the corresponding author on reasonable request.

\section{Authors' contributions}

AR and VG undertook the experimental work. AR, JE, VG and JG designed the project. JE collected the thyroid specimens and relevant clinical data. JG and AR confirm the authenticity of all the raw data. AR and HJ undertook the writing of the manuscript and data analysis. DK undertook microfluidic device design and manufacture. All authors have read and approved the final manuscript.

\section{Ethics approval and consent to participate}

The present project received ethical approval from Northeast-Newcastle and North Tyneside Research Ethics Committee (approval no. 15/NE/0412) and from Hull University Teaching Hospital NHS Trust R\&D (approval no. R1925). Patient tissue samples were taken after obtaining written, informed consent.

\section{Patient consent for publication}

Not applicable.

\section{Competing interests}

The authors declare that they have no competing interests.

\section{References}

1. Wang LY and Ganly I: Nodal metastases in thyroid cancer: Prognostic implications and management. Future Oncol 12: 981-994, 2016.

2. Haugen BR, Alexander EK, Bible KC, Doherty GM, Mandel SJ, Nikiforov YE, Pacini F, Randolph GW, Sawka AM and Schlumberger M: 2015 American thyroid association management guidelines for adult patients with thyroid nodules and differentiated thyroid cancer: The American thyroid association guidelines task force on thyroid nodules and differentiated thyroid cancer. Thyroid 26: 1-133, 2016.

3. Indrasena BSH: Use of thyroglobulin as a tumour marker. World J Biol Chem 8: 81-85, 2017.

4. Kim SJ, Lee KE, Myong JP, Park JH, Jeon YK, Min HS, Park SY, Jung KC, Koo DH and Youn YK: BRAF V600E mutation is associated with tumor aggressiveness in papillary thyroid cancer. World J Surg 36: 310-317, 2012. 
5. Kato MA and Fahey TJ 3rd: Molecular markers in thyroid cancer diagnostics. Surg Clin North Am 89: 1139-1155, 2009.

6. Yip L, Kelly L, Shuai Y, Armstrong MJ, Nikiforov YE, Carty SE and Nikiforova MN: MicroRNA signature distinguishes the degree of aggressiveness of papillary thyroid carcinoma. Ann Surg Oncol 18: 2035-2041, 2011.

7. Acibucu F, Dökmetaş HS, Tutar Y, Elagoz S and Kilicli F: Correlations between the expression levels of micro-RNA146b, 221, 222 and p27Kip1 protein mRNA and the clinicopathologic parameters in papillary thyroid cancers. Exp Clin Endocrinol Diabetes 122: 137-143, 2014

8. Cookson VJ, Bentley MA, Hogan BV, Horgan K, Hayward BE, Hazelwood LD and Hughes TA: Circulating microRNA profiles reflect the presence of breast tumours but not the profiles of microRNAs within the tumours. Cell Oncol (Dordr) 35: 301-308, 2012.

9. Liang H, Zhong Y, Luo Z, Huang Y, Lin H, Zhan S, Xie K and Li QQ: Diagnostic value of 16 cellular tumor markers for metastatic thyroid cancer: An immunohistochemical study. Anticancer Res 31: 3433-3440, 2011

10. Šelemetjev S, Đoric I,Paunovic I, Tatic S and Cvejic D: Coexpressed high levels of VEGF-C and active MMP-9 are associated with lymphatic spreading and local invasiveness of papillary thyroid carcinoma. Am J Clin Pathol 146: 594-602, 2016.

11. Jang JY, Kim DS, Park HY, Shin SC, Cha W, Lee JC, Wang SG and Lee BJ: Preoperative serum VEGF-C but not VEGF-A level is correlated with lateral neck metastasis in papillary thyroid carcinoma. Head Neck 41: 2602-2609, 2019.

12. Shi Y, Su C, Hu H, Yan H, Li W, Chen G, Xu D, Du X and Zhang P: Serum MMP-2 as a potential predictive marker for papillary thyroid carcinoma. PLoS One 13: e0198896, 2018.

13. Riley A, Green V, Cheah R, McKenzie G, Karsai L, England J and Greenman J: A novel microfluidic device capable of maintaining functional thyroid carcinoma specimens ex vivo provides a new drug screening platform. BMC Cancer 22: 259, 2019.

14. Folkman J: Role of angiogenesis in tumor growth and metastasis Semin Oncol 29 (Suppl 16): S15-S18, 2002

15. Kohn EC and Liotta LA: Molecular insights into cancer invasion: Strategies for prevention and intervention. Cancer Res 55: $1856-1862,1995$

16. Ito Y, Miyauchi A, Kihara M, Fukushima M, Higashiyama T and Miya A: Overall survival of papillary thyroid carcinoma patients: A single-institution long-term follow-up of 5897 patients. World J Surg 42: 615-622, 2018

17. Tombran-Tink J, Chader GG and Johnson LV: PEDF: A pigment epithelium-derived factor with potent neuronal differentiative activity. Exp Eye Res 53: 411-414, 1991.

18. Bilak MM, Corse AM, Bilak SR, Lehar M, Tombran-Tink J and Kuncl RW: Pigment epithelium-derived factor (PEDF) protects motor neurons from chronic glutamate-mediated neurodegeneration. J Neuropathol Exp Neurol 58: 719-728, 1999.

19. Zhang L, Chen J, Ke Y, Mansel RE and Jiang WG: Expression of pigment epithelial derived factor is reduced in non-small cell lung cancer and is linked to clinical outcome. Int J Mol Med 17: 937-944, 2006.

20. DawsonDW,VolpertOV,GillisP,CrawfordSE,XuH,BenedictW and Bouck NP: Pigment epithelium-derived factor: A potent inhibitor of angiogenesis. Science 285: 245-248, 1999.

21. Zhang Y, Han J, Yang X, Shao C, Xu Z, Cheng R, Cai W, Ma J, Yang $\mathrm{Z}$ and Gao G: Pigment epithelium-derived factor inhibits angiogenesis and growth of gastric carcinoma by down-regulation of VEGF. Oncol Rep 26: 681-686, 2011.

22. Crawford SE, Stellmach V, Ranalli M, Huang X, Huang L, Volpert O, De Vries GH, Abramson LP and Bouck N: Pigment epithelium-derived factor (PEDF) in neuroblastoma: A multifunctional mediator of schwann cell antitumor activity. J Cell Sci 114(Pt 24): 4421-4428, 2001.

23. Filleur S, Volz K, Nelius T, Mirochnik Y, Huang H, Zaichuk TA, Aymerich MS, Becerra SP, Yap R, Veliceasa D, et al: Two functional epitopes of pigment epithelial-derived factor block angiogenesis and induce differentiation in prostate cancer. Cancer Res 65: 5144-5152, 2005.

24. Cheung LW, Au SC, Cheung AN, Ngan HY, Tombran-Tink J, Auersperg N and Wong AST: Pigment epithelium-derived factor is estrogen sensitive and inhibits the growth of human ovarian cancer and ovarian surface epithelial cells. Endocrinology 147: 4179-4191, 2006.

25. Guan M, Pang CP, Yam HF, Cheung KF, Liu WW and Lu Y: Inhibition of glioma invasion by overexpression of pigment epithelium-derived factor. Cancer Gene Ther 11: 325-332, 2004.
26. Lv Y, Sun Y, Shi T, Shi C, Qin H and Li Z: Pigment epithelium-derived factor has a role in the progression of papillary thyroid carcinoma by affecting the HIF $1 \alpha$-VEGF signaling pathway. Oncol Lett 12: 5217-5222, 2016.

27. Deshmane SL, Kremlev S, Amini S and Sawaya BE: Monocyte chemoattractant protein-1 (MCP-1): An overview. J Interferon Cytokine Res 29: 313-326, 2009.

28. Graves DT, Barnhill R, Galanopoulos T and Antoniades HN: Expression of monocyte chemotactic protein-1 in human melanoma in vivo. Am J Pathol 140: 9-14, 1992.

29. Negus RP, Stamp GW, Relf MG, Burke F, Malik ST, Bernasconi S, Allavena P, Sozzani S, Mantovani A and Balkwill FR: The detection and localization of monocyte chemoattractant protein-1 (MCP-1) in human ovarian cancer. J Clin Invest 95: 2391-2396, 1995.

30. Saji H, Koike M, Yamori T, Saji S, Seiki M, Matsushima K and Toi M: Significant correlation of monocyte chemoattractant protein-1 expression with neovascularization and progression of breast carcinoma. Cancer 92: 1085-1091, 2001

31. Ohta M, Kitadai Y, Tanaka S, Yoshihara M, Yasui W, Mukaida N, Haruma K and Chayama K: Monocyte chemoattractant protein-1 expression correlates with macrophage infiltration and tumor vascularity in human esophageal squamous cell carcinomas. Int J Cancer 102: 220-224, 2002

32. Koide N, Nishio A, Sato T, Sugiyama A and Miyagawa S Significance of macrophage chemoattractant protein-1 expression and macrophage infiltration in squamous cell carcinoma of the esophagus. Am J Gastroenterol 99: 1667-1674, 2004.

33. Lu Y, Cai Z, Galson DL, Xiao G, Liu Y, George DE, Melhem MF, Yao Z and Zhang J: Monocyte chemotactic protein-1 (MCP-1) acts as a paracrine and autocrine factor for prostate cancer growth and invasion. Prostate 66: 1311-1318, 2006

34. Ueno T, Toi M, Saji H, Muta M, Bando H, Kuroi K, Koike M, Inadera $\mathrm{H}$ and Matsushima K: Significance of macrophage chemoattractant protein-1 in macrophage recruitment, angiogenesis, and survival in human breast cancer. Clin Cancer Res 6 : 3282-3289, 2000.

35. Tanaka K, Kurebayashi J, Sohda M, Nomura T, Prabhakar U, Yan L and Sonoo H: The expression of monocyte chemotactic protein-1 in papillary thyroid carcinoma is correlated with lymph node metastasis and tumor recurrence. Thyroid 19: 21-25, 2009.

36. Ryder M, Gild M, Hohl TM, Pamer E, Knauf J, Ghossein R, Joyce JA and Fagin JA: Genetic and pharmacological targeting of CSF-1/CSF-1R inhibits tumor-associated macrophages and impairs BRAF-induced thyroid cancer progression. PLoS One 8: e54302, 2013

37. Dawes J, Pratt DA, Dewar MS and Preston FE: Do extra-platelet sources contribute to the plasma level of thrombospondin? Thromb Haemost 59: 273-276, 1988 .

38. Chen H, Herndon ME and Lawler J: The cell biology of thrombospondin-1. Matrix Biol 19: 597-614, 2000

39. Nucera C, Porrello A, Antonello ZA, Mekel M, Nehs MA, Giordano TJ, Gerald D, Benjamin LE, Priolo C, Puxeddu E, et al: B-Raf(V600E) and thrombospondin-1 promote thyroid cancer progression. Proc Natl Acad Sci USA 107: 10649-10654, 2010.

40. Soula-Rothhut M, Coissard C, Sartelet H, Boudot C, Bellon G, Martiny L and Rothhut B: The tumor suppressor PTEN inhibits EGF-induced TSP-1 and TIMP-1 expression in FTC-133 thyroid carcinoma cells. Exp Cell Res 304: 187-201, 2005

41. Bienes-Martínez R, Ordóñez A, Feijoo-Cuaresma M, Corral-Escariz M, Mateo G, Stenina O, Jiménez B and Calzada MJ: Autocrine stimulation of clear-cell renal carcinoma cell migration in hypoxia via HIF-independent suppression of thrombospondin-1. Sci Rep 2: 788, 2012.

42. Tzeng HT, Tsai CH, Yen YT, Cheng HC, Chen YC, Pu SW, Wang YS, Shan YS, Tseng YL, Su WC, et al: Dysregulation of Rab37-mediated cross-talk between cancer cells and endothelial cells via thrombospondin-1 promotes tumor neovasculature and metastasis. Clin Cancer Res 23: 2335-2345, 2017

43. Huang T, Sun L, Yuan X and Qiu H: Thrombospondin-1 is a multifaceted player in tumor progression. Oncotarget 8: 84546-84558, 2017.

44. Schlaeppi JM and Wood JM: Targeting vascular endothelial growth factor (VEGF) for anti-tumor therapy, by anti-VEGF neutralizing monoclonal antibodies or by VEGF receptor tyrosine-kinase inhibitors. Cancer Metastasis Rev 18: 473-481, 1999.

45. Shweiki D, Itin A, Soffer D and Keshet E: Vascular endothelial growth factor induced by hypoxia may mediate hypoxia-initiated angiogenesis. Nature 359: 843-845, 1992. 
46. Soh EY, Duh QY, Sobhi SA, Young DM, Epstein HD, Wong MG, Garcia YK, Min YD, Grossman RF, Siperstein AE and Clark OH: Vascular endothelial growth factor expression is higher in differentiated thyroid cancer than in normal or benign thyroid. J Clin Endocrinol Metab 82: 3741-3747, 1997.

47. Tuttle RM, Fleisher M, Francis GL and Robbins RJ: Serum vascular endothelial growth factor levels are elevated in metastatic differentiated thyroid cancer but not increased by short-term TSH stimulation. J Clin Endocrinol Metab 87: 1737-1742, 2002.

48. Xie J, Liu Y, Du X and Wu Y: TGF- $\beta 1$ promotes the invasion and migration of papillary thyroid carcinoma cells by inhibiting the expression of IncRNA-NEF. Oncol Lett 17: 3125-3132, 2019.

49. Zhang W, van Weerden WM, de Ridder CMA, Erkens-Schulze S, Schönfeld E, Meijer TG, Kanaar R, van Gent DC and Nonnekens J: Ex vivo treatment of prostate tumor tissue recapitulates in vivo therapy response. Prostate 79: 390-402, 2019.

50. Liu X, Su C, Xu J, Zhou D, Yan H, Li W, Chen G, Zhang N, Xu D and $\mathrm{Hu} \mathrm{H}$ : Immunohistochemical analysis of matrix metalloproteinase-9 predicts papillary thyroid carcinoma prognosis. Oncol Lett 17: 2308-2316, 2019.

51. Selemetjev S, Savin S, Paunovic I, Tatic S and Cvejic D: Concomitant high expression of survivin and vascular endothelial growth factor-C is strongly associated with metastatic status of lymph nodes in papillary thyroid carcinoma. J Cancer Res Ther 14 (Suppl): S114-S119, 2018.

52. Guan H, Guo Y, Liu L, Ye R, Liang W, Li H, Xiao H and Li Y: INAVA promotes aggressiveness of papillary thyroid cancer by upregulating MMP9 expression. Cell Biosci 8: 26, 2018.

53. Cui M, Chang Y, Du W, Liu S, Qi J, Luo R and Luo S Upregulation of lncRNA-ATB by transforming growth factor $\beta 1$ (TGF- $\beta 1$ ) promotes migration and invasion of papillary thyroid carcinoma cells. Med Sci Monit 24: 5152-5158, 2018.
54. Lu ZL, Chen YJ, Jing XY, Wang NN, Zhang T and Hu CJ: Detection and identification of serum peptides biomarker in papillary thyroid cancer. Med Sci Monit 24: 1581-1587, 2018.

55. Wang N, Jiang R, Yang JY, Tang C, Yang L, Xu M, Jiang QF and Liu ZM: Expression of TGF- 31 , SNAI1 and MMP-9 is associated with lymph node metastasis in papillary thyroid carcinoma. J Mol Histol 45: 391-399, 2014.

56. Makki FM, Taylor SM, Shahnavaz A, Leslie A, Gallant J, Douglas S, Teh E, Trites J, Bullock M, Inglis K, et al: Serum biomarkers of papillary thyroid cancer. J Otolaryngol Head Neck Surg 42: 16, 2013.

57. Zhou ZH, Cui XN, Xing HG, Yan RH, Yao DK and Wang LX: Changes and prognostic value of serum vascular endothelial growth factor in patients with differentiated thyroid cancer. Med Princ Pract 22: 24-28, 2012.

58. Liang H, Zhong Y, Luo Z, Huang Y, Lin H, Luo M, Zhan S, Xie K, Ma Y and Li QQ: Assessment of biomarkers for clinical diagnosis of papillary thyroid carcinoma with distant metastasis. Int J Biol Markers 25: 38-45, 2010.

59. Wang T, Jiang CX, Li Y and Liu X: Pathologic study of expression and significance of matrix metalloproteinases-9, tissue inhibitor of metalloproteinase-1, vascular endothelial growth factor and transforming growth factor beta- 1 in papillary carcinoma and follicular carcinoma of thyroid. Zhonghua Bing Li Xue Za Zhi 38: 824-828, 2009 (In Chinese).

60. Wang JX, Dong R, Liu QL, Yang SB, Fan YX, Zhang Q, Yang FQ, Wu P, Yu JK and Zheng S: Detection and identification of specific serum biomarkers in papillary thyroid cancer. Zhonghua Zhong Liu Za Zhi 31: 265-268, 2009 (In Chinese). 